\title{
COVID-19 en la niñez y adolescencia
}

\section{DOI 10.5377/alerta.v4i1.9780}

\section{José Eduardo Oliva Marín ${ }^{1}$}

1. Departamento de Gobernanza y Gestión del Conocimiento, Instituto Nacional de Salud, San Salvador, El Salvador.

${ }^{*}$ Correspondencia

$\square$ joseduardoliva67@gmail.com

1. (1) 0000-0002-6005-0558

\section{ACCESO ABIERTO}

\section{COVID-19 in childhood and adolescence}

\section{Citación recomendada:}

Oliva Marín JE. COVID-19 en la

niñez y adolescencia. Alerta.

2021;4 (1):49-61. DOI 10.5377/

alerta.v4i1.9780

\section{Contribución de autoría:}

JEOM: elaboración del

manuscrito y rendición de

cuentas del mismo.

\section{Recibido:}

3 de septiembre de 2020

\section{Aceptado:}

5 de enero de 2021

\section{Publicado:}

22 de enero 2021

Conflicto de intereses:

El autor declara no tener conflictos de interés con ninguna organización.

\begin{abstract}
Resumen
El compromiso en los niños y adolescentes se ha hecho más evidente a medida que la epidemia de COVID-19 progresó a pandemia. A casi un año de haberse iniciado, los niños comprenden del $1 \%$ al $6 \%$ de los casos. La mayoría de casos en pediatría son leves y el sexo masculino se ve más afectado que el femenino. Los niños de menor edad, como los lactantes y preescolares, son proclives a desarrollar cuadros clínicos más graves. La gama de manifestaciones clínicas en los pacientes pediátricos es tan diversa como en los adultos, y ha llevado ya a varios niños y adolescentes a la muerte, usualmente asociada a comorbilidades, coinfecciones o a una extensa respuesta inflamatoria sistémica. En lo que respecta a la distribución temporal, hay una tendencia de rápido aumento de los casos durante las primeras etapas de la epidemia en cada país, seguida de una gradual y constante disminución. En abril de 2020 se identificó un nuevo síndrome en niños y adolescentes de 2 a 15 años asociado a COVID-19. Si bien el síndrome es muy raro, puede ser peligroso. La afección se ha denominado síndrome inflamatorio multisistémico en niños o síndrome inflamatorio multisistémico pediátrico.

Palabras clave

Infecciones por coronavirus, niño, adolescente, inflamación.
\end{abstract}

Durante enero de 2020 el brote de neumonía por SARS-CoV-2 en la ciudad de Wuhan, provincia de Hubei, China, pareció obviar a los niños y a los adolescentes. En la primera caracterización epidemiológica de COVID-19, publicada el 17 febrero de 2020 por los Centros de Control y Prevención de Enfermedades de China (CDC/China, por sus siglas en inglés)' ${ }^{1}$, se incluyeron 44672 casos corroborados por RT- PCR hasta el 11 de febrero de 2020 . Se reportaron 416 casos $(0,9 \%)$ entre las edades de 0 a 9 años, ninguna muerte y 549 casos $(1,2 \%)$ entre las edades de 10 a 19 años, incluyendo la muerte de un adolescente (tasa de letalidad del $0,002 \%)$. 
Sin embargo, esta impresión inicial se modificó a medida el brote progresó a nivel global; hoy, a casi un año, los niños comprenden del $1 \%$ al $6 \%$ de todos los casos positivos $^{2-4}$. Sin embargo, se desconoce el número real de casos, ya que hay infecciones asintomáticas. Los pacientes menores de 1 año pueden ser asintomáticos hasta en el $15 \%$ de los $\operatorname{casos}^{2,5}$. Los pacientes pediátricos rara vez se someten a pruebas diagnósticas para COVID-19, ya que frecuentemente son asintomáticos o levemente sintomáticos. Además, los niños que se infectan con SARS-CoV-2 tienen más compromiso del tracto respiratorio superior que del tracto respiratorio inferior ${ }^{5}$. Sin embargo, aun siendo asintomáticos o levemente sintomáticos, los pacientes excretan al virus de manera prolongada en sus secreciones respiratorias y heces $s^{6,7}$, teniendo implicaciones notables en la difusión del virus en la comunidad, específicamente en guarderías, escuelas y en sus hogares ${ }^{8,9}$.

En la presente revisión narrativa sobre COVID-19 en niños y adolescentes, a diciembre de 2020, se describen los siguientes aspectos: epidemiología, sistema de clasificación de gravedad, manifestaciones clínicas, alteraciones de laboratorio y hallazgos de imagen. En lo referente al tratamiento, al presente aún existe carencia de experiencia terapéutica específica en pediatría. Se describe, además, el síndrome inflamatorio multisistémico en niños, también conocido como síndrome inflamatorio multisistémico pediátrico temporalmente asociado a SARS-CoV-2.

\section{Descripción de la temática}

\section{Epidemiología}

Dong et al. ${ }^{5}$, el 8 de abril de 2020, registraron una serie de casos a nivel nacional de 2135 pacientes pediátricos con COVID-19, reportados al CDC/China del 16 de enero al 8 de febrero de 2020.

Hubo 728 (34,1 \%) casos confirmados por laboratorio y 1407 (65,9\%) casos sospechosos. El rango de edad fue de 2 a 13 años y $1208(56,6 \%)$ de los pacientes eran del sexo masculino. En lo que respecta a la distribución temporal, hubo una tendencia de rápido aumento de los casos durante la primera etapa de la epidemia, seguida de una gradual y constante disminución.

Con respecto a la gravedad (incluyendo casos confirmados y casos sospechosos) $94(4,4 \%), 1088$ (51 \%) y $826(38,7 \%)$ casos ,fueron diagnosticados como asintomáticos, leves o moderados, respectivamente; totalizando el 94,1\% de todos los casos no graves. Aunque las manifestaciones clínicas de COVID-19 en niños fueron menos graves que las de los adultos, los niños más pequeños, especialmente los lactantes y los preescolares, fueron más proclives a presentar manifestaciones graves (neumonía y cianosis central) o críticas Sindrome de Dificultad Respiratoria Aguda (SDRA) que requirió ventilación mecánica. Las proporciones de casos graves y críticos fueron 10,6\%, 7,3\%, $4,2 \%, 4,1 \%$ y $3,0 \%$, para los grupos de edad $<1$ de un año, 1 a 5 años, 6 a 10 años, 11 a 15 años y > 16 años, respectivamente. Un adolescente de 14 años de la provincia de Hubei murió el 7 de febrero de 2020, muerte incluida en la caracterización epidemiológica del CDC/China'.

Los Centros para la Prevención y Control de Enfermedades de Atlanta (CDC, por sus siglas en inglés) publicaron en su Morbidity and Mortality Weekly Report (MMWR, por sus siglas en inglés), el 10 de abril 202010, datos de 149760 casos de COVID-19 confirmados por laboratorio en los Estados Unidos, desde el 12 de febrero al 2 de abril de 2020. De esos, $2572(1,7 \%)$ fueron niños o adolescentes $<18$ años de edad. El sexo se documentó en solo 2490; de estos, 1408 (56,5\%) fueron del sexo masculino. De los 2572, el 5,7\% fue ingresado a servicios de pediatría y un $0,58 \%$ a unidades de cuidados intensivos pediátricos (UCIP). Se informaron tres muertes entre los casos pediátricos.

La mediana de edad fue de 11 años (rango de 0-17 años). Casi un tercio de los casos pediátricos reportados (813; 32 \%) ocurrió en adolescentes de 15 a 17 años, seguidos de aquellos casos en niños o adolescentes de 10 a 14 años (682; $27 \%$ ). Entre los menores de 10 años, 388 (15\%) ocurrieron en niños de 5 a 9 años; 291 (11\%) en niños de 1 a 4 años y 398 (15,5\%) en niños menores de 1 año. Los menores de 1 año representaron el porcentaje más alto de hospitalizaciones (15\%) por COVID-19. El porcentaje de pacientes hospitalizados con edades entre 1 y 17 años, fue menor, entre el 4,1 \% y el $14 \%$ ).

Entre los 184 casos de niños < 18 años con información de exposición conocida, 16 (9\%) se asociaron a un viaje y 168 (91\%) tuvieron exposición a un paciente COVID-19 en el hogar o en la comunidad.

Entre los 345 casos pediátricos que contaban con documentación sobre condiciones subyacentes, incluidos los seis pacientes ingresados en UCIP, 80 (23\%) tenían al menos una condición subyacente. Las más comunes fueron: enfermedad pulmonar crónica (incluido el asma), enfermedad cardiovascular e inmunosupresión.

Parri et al.11, el 1 de mayo de 2020, publicaron los resultados de un estudio de infección por coronavirus en los departa- 
mentos de emergencias pediátricas de Italia (CONFIDENCE, por sus siglas en inglés). El estudio consistió de una cohorte de 100 niños $<18$ años de edad con COVID-19, confirmado por RT-PCR, evaluados entre el 3 y el 27 de marzo de 2020, en 17 departamentos de emergencias pediátricas de Italia. El $21 \%$ de los pacientes fueron asintomáticos, $58 \%$ presentaron enfermedad leve, $19 \%$ enfermedad moderada, $1 \%$ enfermedad grave y $1 \%$ estado crítico. La mayoría de los lactantes presentó enfermedad leve, lo cual contrasta con lo encontrado por Dong et al. ${ }^{5}$ y los $C D C^{10}$, quienes describieron que los lactantes $<1$ año fueron los que presentaron casos de mayor gravedad. Evoluciones graves o críticas se diagnosticaron sobre todo en pacientes con comorbilidades. No se reportaron muertes.

\section{Sistema de clasificación de grave- dad para COVID-19 en pediatría}

Los pacientes menores de 18 años pueden ser evaluados de acuerdo a las pautas de puntuación para pacientes pediátricos que adolecen de la COVID-19, emitidas por la Sociedad de Pediatría de la Asociación Médica China ${ }^{5,12}$. Definieron la gravedad de COVID-19 con base en las características clínicas, pruebas de laboratorio y de imagen. Los criterios de diagnóstico son los siguientes: 1. Infección asintomática: ningún síntoma o signo clínico y las imágenes de tórax normales, RT-PCR o serología positivos. 2. Caso leve: sintomatología de infección aguda del tracto respiratorio superior, incluyendo: fiebre, fatiga, mialgia, tos, dolor de garganta, secreción nasal y estornudos. El examen físico revela faringitis y ausencia de sonidos anormales en los pulmones. Algunos niños pueden no tener fiebre o tener solo síntomas gastrointestinales como náuseas, vómitos, dolor abdominal y/o diarrea. 3. Caso moderado: Paciente con neumonía, fiebre frecuente y tos (principalmente tos seca al principio, seguida de tos con flema); algunos pueden presentar sibilancias, pero no hipoxemia o dificultad para respirar; en los pulmones se pueden escuchar estertores secos y/o húmedos. Algunos casos no tienen síntomas ni signos clínicos, pero la tomografía axial computarizada (TAC) de tórax revela lesiones pulmonares, las cuales son subclínicas. 4. Caso grave: Fiebre, sintomatología respiratoria temprana, como tos; pueden ser acompañados de sintomatología gastrointestinal como diarrea. A menudo se complican en aproximadamente una semana, desarrollando disnea con cianosis central. La saturación de oxígeno es < $92 \%$, acompañándose de otras manifestaciones de hipoxia. 5. Caso crítico: Los niños pueden progresar rápidamente a SDRA o falla respiratoria y pueden también presentar choque, encefalopatía, lesión miocárdica o insuficiencia cardíaca, coagulopatía e insuficiencia renal aguda. La disfunción orgánica puede ser mortal.

Buonsenso et al. ${ }^{13}$ propusieron el 15 de mayo de 2020 que la definición de enfermedad moderada debía cambiarse a un diagnóstico exclusivamente clínico. En la definición de enfermedad moderada, se detalla que «algunos casos no tienen síntomas ni signos clínicos, pero la TAC de tórax revela lesiones pulmonares, que son subclínicas». Especifican que este criterio debe eliminarse, ya que estos niños asintomáticos o paucisintomáticos no deberían someterse a una TAC, sino ser clasificados directamente como casos leves.

\section{Manifestaciones clínicas}

Hoang et al.14, en una revisión sistemática publicada en junio de 2020, identificaron las manifestaciones clínicas más frecuentes reportadas en 131 estudios, llevados a cabo en 26 países, comprendiendo 7780 pacientes pediátricos. La fiebre y la tos fueron los dos signos más predominantes, presentándose en el $59,1 \%$ y el $55,9 \%$ de los niños, respectivamente. Se observó que alrededor del 19,3\% de los niños eran asintomáticos, efectuándoles RT-PCR debido a antecedentes de contacto cercano. Luego, en orden descendente, la sintomatología más frecuentemente encontrada fue: rinorrea y congestión nasal (20\%), mialgia y fatiga $(18,7 \%)$, odinofagia $(18,2 \%)$, disnea o dificultad respiratoria $(11,7 \%)$, dolor abdominal y diarrea $(6,5 \%)$, náuseas y vómitos $(5,4 \%)$, cefalea y mareos $(4,3 \%)$, faringitis $(3,3 \%)$, falta de apetito $(1,7 \%)$ y exantema $(0,25 \%)$.

\section{Hallazgos de laboratorio}

Aunque en general el recuento total de leucocitos varía entre pacientes, la linfopenia, acompañada de trombocitopenia leve, se encuentran entre los hallazgos anormales más comunes en los pacientes pediátricos con COVID-19. Se ha reportado neutrofilia en algunos pacientes, así como prolongación en el tiempo de protrombina y el tiempo parcial de tromboplastina activada. El dímero $D$ elevado refleja la aparición de coagulopatía y es un importante indicador de progresión de la enfermedad. Además, los marcadores inflamatorios se presentan elevados en las fases agudas del proceso infeccioso: velocidad de eritrosedimentación (VES), proteína $C$ reactiva $(P C R)$ y la 
procalcitonina. Cabe mencionar que si bien el valor diagnóstico de la PCR es superior al de la procalcitonina, esta última puede potencialmente ser de mayor valor que la primera, para predecir progresión de la enfermedad ${ }^{15}$.

\section{Imagenología}

Katal et al. ${ }^{16}$, en una revisión sistemática publicada en julio de 2020, identificaron los hallazgos de imagen más frecuentes reportados en pacientes COVID-19 pediátricos. La revisión analizó 39 estudios incluyendo un total de 850 pacientes. Las opacidades en vidrio esmerilado y las consolidaciones fueron las anomalías más frecuentemente encontradas en la TAC de tórax (61,5\%). Otros hallazgos descritos fueron: el signo del halo (área circular de opacidad en vidrio esmerilado localizada alrededor de nódulos pulmonares) ${ }^{17}$, opacidades intersticiales, engrosamiento de las paredes bronquiales y el patrón en adoquín desordenado (patrón reticular superpuesto sobre un fondo de opacidad en vidrio esmerilado, dando un aspecto de figuras poliédricas que asemejan a los adoquines o empedrados de los pavimentos) ${ }^{18}$. Aproximadamente el $55 \%$ de los pacientes presentaron hallazgos pulmonares unilaterales. La mayoría de estudios reportó que las lesiones se distribuían de forma periférica y en los lóbulos pulmonares inferiores. El 26,5\% de los pacientes presentó una TAC de tórax normal.

\section{Tratamiento}

Actualmente, remdesivir es el único fármaco aprobado por la Administración de Alimentos y Medicamentos de los Estados Unidos (FDA, por sus siglas en inglés) para el tratamiento de COVID-19 en pacientes hospitalizados. Está aprobado para adolescentes con COVID-19 $\geq 12$ años y con peso $\geq 40 \mathrm{~kg}$. Remdesivir también está disponible para pacientes más pequeños (que pesen <40 kg pero más de $>3,5 \mathrm{~kg}$ ), a través de una autorización de uso de emergencia, también emitida por la FDA. No hay datos suficientes para recomendar el uso de otros medicamentos, antivirales o inmunomoduladores, como terapéuticos específicos contra COVID-19 en pacientes pediátricos. Las consideraciones generales como las condiciones subyacentes, la gravedad de la enfermedad y el potencial de toxicidad o de interacciones farmacológicas, deben orientar las decisiones terapéuticas caso por caso ${ }^{19}$.

En la Tabla 1 se resumen de características clínicas, exámenes de laboratorio, hallazgos de imagenología y tratamientos, utilizados en niños y adolescentes con COVID-19 confirmado por RT-PCR, en diversos reportes de casos o series de casos alrededor del mundo.

\section{COVID-19 en unidad de cuidados intensivos pediátricos}

Shekerdemian et al. ${ }^{34}$, el 11 de mayo de 2020, reportaron un estudio transversal llevado a cabo entre el 14 de marzo y el 3 de abril de 2020, de 48 niños que ingresaron a 14 UCIP en los Estados Unidos. De los 48 niños con COVID-19 admitidos en las UCIP participantes, 21 tenían < 10 años, 27 tenían > 10 años, 25 (52\%) eran varones y los rangos de edad oscilaron entre los 4 y 16 años. Cuarenta pacientes (83\%) tenían comorbilidades preexistentes significativas (enfermedad cardíaca, retraso del desarrollo, diabetes, compromiso inmunitario, neoplasia maligna, obesidad, estado postrasplante o traqueotomía). Hubo un paciente asintomático (2 \%), 35 (73 \%) presentaron sintomatología respiratoria, uno (2\%) sintomatología gastrointestinal, dos (4\%) sintomatología neurológica, dos (4\%) sintomatología circulatoria, 7 (15\%) otras sintomatologías y 18 (38\%) requirieron ventilación invasiva. Once pacientes (23 \%) tuvieron falla de dos o más sistemas de órganos. Se requirió oxigenación por membrana extracorpórea para un paciente (2\%). Al finalizar el período de seguimiento, dos pacientes (4\%) habían muerto y quince (31 \%) seguían hospitalizados, tres todavía necesitaban asistencia respiratoria y uno recibía oxigenación por membrana extracorpórea. El promedio de estancia en UCIP y la duración de la estancia hospitalaria fueron de 5 (3-9) días y 7 (4-13) días, respectivamente.

\section{Síndrome inflamatorio multisistémico en niños}

Riphagen et al. ${ }^{35}$, durante abril de 2020 en Londres, Inglaterra, reportaron a un grupo de ocho niños con choque hiperinflamatorio, mostrando características similares a la enfermedad atípica de Kawasaki, al síndrome de choque por enfermedad de Kawasaki (KDSS, por sus siglas en inglés) ${ }^{36}$ o al síndrome de choque tóxico. Seis de ellos resultaron negativos a SARS-CoV-2 por RT-PCR. En los dos pacientes que resultaron positivos, los electrocardiogramas basales fueron inespecíficos; sin embargo, un hallazgo ecocardiográfico en común fue el de vasos coronarios refringentes, frecuentemente observado en la enfermedad de Kawasaki. Uno de los dos pacientes positivos presentó arritmias con choque refractario, requirió soporte vital extracorpóreo y murió eventualmente de un 
Tabla 1. Resumen de características clínicas, de laboratorio e imagenología, así como de tratamiento, presentadas por niños y adolescentes con COVID-19 confirmado por RT-PCR

\begin{tabular}{|c|c|c|c|c|c|c|c|c|c|c|}
\hline Fuente & Publicación & País & \#Ptes. & $\begin{array}{l}<10 \\
\text { años }\end{array}$ & $\begin{array}{l}\text { 10-19 } \\
\text { años }\end{array}$ & Rango & Sexo & Sintomatología/ tratamiento & Laboratorio & Imagenología \\
\hline $\begin{array}{l}\text { Shen } \\
\text { et al. }\end{array}$ & $5 / 2 / 20$ & China & 28 & ND & ND & $\begin{array}{l}1 \text { mes } \\
\text { a } 17 \\
\text { años }\end{array}$ & ND & $\begin{array}{l}\text { Fiebre, fatiga, tos seca, congestión } \\
\text { nasal, rinorrea; rara vez náuseas, } \\
\text { vómitos y diarrea. } \\
\text { No existen datos sobre el } \\
\text { tratamiento. }\end{array}$ & PCR elevada & $\begin{array}{l}\text { Rayos X de tórax: } \\
\text { opacidad en vidrio } \\
\text { esmerilado o } \\
\text { neumonía. }\end{array}$ \\
\hline $\begin{array}{l}\text { Chan } \\
\text { etal. }\end{array}$ & $15 / 2 / 20$ & China & 1 & 0 & 1 & $\begin{array}{l}10 \\
\text { años }\end{array}$ & $1 \mathrm{M}$ & $\begin{array}{l}\text { Asintomático, sin embargo con } \\
\text { lesiones pulmonares en los rayos } \\
\text { X de tórax. } \\
\text { No recibió tratamiento. }\end{array}$ & $\begin{array}{l}\text { Fosfatasa alcalina } \\
\text { elevada }\end{array}$ & $\begin{array}{l}\text { Rayos X de tórax: } \\
\text { opacidades } \\
\text { pulmonares en } \\
\text { vidrio esmerilado. }\end{array}$ \\
\hline $\begin{array}{l}\text { Feng } \\
\text { etal. }\end{array}$ & $16 / 2 / 20$ & China & 15 & ND & ND & $\begin{array}{l}\text { 4-14 } \\
\text { años }\end{array}$ & $\begin{array}{l}5 \mathrm{M} \\
10 \mathrm{~F}\end{array}$ & $\begin{array}{l}\text { Cinco de los pacientes presentaron } \\
\text { solo fiebre, los } 10 \text { restantes fueron } \\
\text { asintomáticos. } \\
\text { Tuvieron cinco días de tratamiento, } \\
\text { sin especificar qué tipo de } \\
\text { medicamentos recibieron. }\end{array}$ & Leucopenia & $\begin{array}{l}\text { TAC de tórax: } \\
\text { opacidades } \\
\text { nodulares } \\
\text { pequeñas y } \\
\text { opacidades } \\
\text { irregulares, } \\
\text { ambas en vidrio } \\
\text { esmerilado. }\end{array}$ \\
\hline $\begin{array}{l}\text { Xia } \\
\text { et al. }\end{array}$ & $5 / 3 / 20$ & China & 20 & 19 & 1 & $\begin{array}{l}0 \text { a } 14 \\
\text { años }\end{array}$ & $\begin{array}{l}13 M \\
7 F\end{array}$ & $\begin{array}{l}\text { Fiebre, tos, diarrea, secreción } \\
\text { nasal, dolor de garganta, } \\
\text { vómitos, taquipnea y fatiga. Poco } \\
\text { frecuentes: estertores húmedos, } \\
\text { signos de retracción costal y } \\
\text { cianosis. } \\
\text { Ocho pacientes presentaron } \\
\text { coinfección con otros patógenos } \\
\text { (incluidos los virus de influenza } \\
\text { A y B, micoplasma, virus sincitial } \\
\text { respiratorio y citomegalovirus. } \\
\text { Recibieron tratamiento, sin } \\
\text { especificar que medicamentos. }\end{array}$ & $\begin{array}{l}\text { Linfopenia; alanina } \\
\text { aminotransferasa, } \\
\text { CK-MB, PCR y } \\
\text { procalcitoninas, } \\
\text { elevadas. }\end{array}$ & $\begin{array}{l}\text { TAC de tórax: } \\
\text { se observó } \\
\text { consolidación con } \\
\text { el signo del halo } \\
\text { circundante, } \\
\text { se observaron } \\
\text { opacidades en } \\
\text { vidrio esmerilado. }\end{array}$ \\
\hline $\begin{array}{l}\text { Qiu } \\
\text { et al. }^{24}\end{array}$ & $25 / 3 / 20$ & China & 36 & ND & ND & $\begin{array}{l}1 \text { a } 16 \\
\text { años }\end{array}$ & $\begin{array}{l}23 \mathrm{M} \\
13 \mathrm{~F}\end{array}$ & $\begin{array}{l}\text { Diez pacientes fueron } \\
\text { asintomáticos. El resto presentaron: } \\
\text { fiebre, tos seca o ambas, así como } \\
\text { otros síntomas menos frecuentes: } \\
\text { dolor de garganta, faringitis, disnea } \\
\text { o taquipnea y vómitos o diarrea. } \\
\text { Todos los niños recibieron } \\
\text { interferón-alfa por aerosolización } \\
\text { dos veces al día, } 14 \text { (39\%) } \\
\text { recibieron lopinavir-ritonavir } \\
\text { en jarabe dos veces al día y seis } \\
\text { (17\%), requirieron oxígeno. }\end{array}$ & $\begin{array}{l}\text { Linfopenia, } \\
\text { leucopenia; CK-MB, } \\
\text { procalcitonina y } \\
\text { dímero-D, elevados. }\end{array}$ & $\begin{array}{l}\text { TAC de tórax } \\
\text { neumonía } \\
\text { reportada en } 19 \\
\text { pacientes como } \\
\text { opacidades } \\
\text { pulmonares en } \\
\text { vidrio esmerilado. }\end{array}$ \\
\hline $\begin{array}{l}\text { Liu } \\
\text { et al. }\end{array}$ & $2 / 4 / 20$ & China & 6 & 6 & 0 & $\begin{array}{l}1 \text { a } 7 \\
\text { años }\end{array}$ & $\begin{array}{l}2 \mathrm{M} \\
4 \mathrm{~F}\end{array}$ & $\begin{array}{l}\text { Fiebre y tos fue lo más frecuente; } \\
\text { de manera esporádica: amígdalas } \\
\text { inflamadas, faringitis, vómitos, } \\
\text { sibilancias, taquipnea, rinorrea, } \\
\text { escalofríos. } \\
\text { Un niño fue ingresado en la UCIP } \\
\text { y recibió IGIV. Todos los pacientes } \\
\text { fueron tratados empíricamente } \\
\text { con antivirales, antibióticos y } \\
\text { terapias de apoyo. }\end{array}$ & $\begin{array}{l}\text { Anemia, linfopenia, } \\
\text { leucopenia, } \\
\text { neutropenia; } \\
\text { dímero-D, aspartato } \\
\text { aminotransferasasa } \\
\text { y PCR, elevados. }\end{array}$ & $\begin{array}{l}\text { TAC de tórax: } \\
\text { opacidades } \\
\text { irregulares en } \\
\text { vidrio esmerilado. }\end{array}$ \\
\hline
\end{tabular}




\begin{tabular}{|c|c|c|c|c|c|c|c|c|c|c|}
\hline Fuente & Publicación & País & \#Ptes. & $\begin{array}{l}<10 \\
\text { años }\end{array}$ & $\begin{array}{l}\text { 10-19 } \\
\text { años }\end{array}$ & Rango & Sexo & Sintomatología/ tratamiento & Laboratorio & Imagenología \\
\hline $\begin{array}{l}\text { Lu } \\
\text { et al. }\end{array}$ & $23 / 4 / 20$ & China & 171 & 129 & 42 & $\begin{array}{l}1 \text { día a } \\
15 \\
\text { años }\end{array}$ & $\begin{array}{l}104 \mathrm{M} \\
67 \mathrm{~F}\end{array}$ & $\begin{array}{l}\text { Fueron asintomáticos } 27 \text { pacientes. } \\
\text { El resto presentó: fiebre, tos } \\
\text { y eritema faríngeo. Otras } \\
\text { manifestaciones menos frecuentes } \\
\text { fueron: diarrea, fatiga, rinorrea, } \\
\text { vómitos y congestión nasal. } \\
\text { Tres pacientes se ingresaron en la } \\
\text { UCIP con ventilación mecánica. } \\
\text { Los tres tenían comorbilidades } \\
\text { (hidronefrosis, leucemia e } \\
\text { invaginación intestinal). El niño con } \\
\text { invaginación intestinal desarrolló } \\
\text { falla multiorgánica y falleció. } \\
\text { No existen datos sobre el } \\
\text { tratamiento recibido por ninguno } \\
\text { de los pacientes. }\end{array}$ & Linfopenia & $\begin{array}{l}\text { TAC de tórax: } \\
\text { opacidad en } \\
\text { vidrio esmerilado } \\
\text { bilateral. }\end{array}$ \\
\hline $\begin{array}{l}\text { Nathan } \\
\text { et al. }\end{array}$ & $27 / 4 / 20$ & Francia & 5 & 5 & 0 & $\begin{array}{l}<3 \\
\text { meses }\end{array}$ & $5 \mathrm{M}$ & $\begin{array}{l}\text { Los cinco pacientes presentaron: } \\
\text { fiebre aislada e irritabilidad, } \\
\text { rinorrea, tos y piel moteada. } \\
\text { Cuatro de los niños mostraron } \\
\text { sintomatología neurológica al } \\
\text { ingreso como: hipotonía axial o } \\
\text { somnolencia o ambas; además, } \\
\text { cuatro de ellos presentaron } \\
\text { gemidos. } \\
\text { Los pacientes recibieron solo } \\
\text { acetaminofén. }\end{array}$ & $\begin{array}{l}\text { Líquido } \\
\text { cefalorraquídeo } \\
\text { normal. }\end{array}$ & $\begin{array}{l}\text { Rayos X de tórax: } \\
\text { normales, excepto } \\
\text { hiperaereación } \\
\text { leve en un } \\
\text { paciente. }\end{array}$ \\
\hline $\begin{array}{l}\text { Parri } \\
\text { et al. }{ }^{11}\end{array}$ & $1 / 5 / 20$ & Italia & 100 & 76 & 24 & $\begin{array}{l}0 \text { a } \\
17.5 \\
\text { años }\end{array}$ & $\begin{array}{l}57 \mathrm{M} \\
43 \mathrm{~F}\end{array}$ & $\begin{array}{l}\text { Fueron asintomáticos el } 21 \% \text {, } \\
\text { y sintomáticos el } 79 \% \text {, quienes } \\
\text { presentaron: fiebre, tos, dificultad } \\
\text { para respirar, ausencia de apetito } \\
\text { o dificultad para alimentarse, } \\
\text { esté último sobre todo en los } \\
\text { lactantes. Otros presentaron: } \\
\text { nauseas, vómitos, fatiga, diarrea, } \\
\text { deshidratación, dolor abdominal, } \\
\text { cefalea, odinofagia, exantema, } \\
\text { cianosis, apnea. } \\
\text { Recibieron asistencia respiratoria } \\
\text { nueve pacientes, seis de ellos } \\
\text { tenían condiciones coexistentes. } \\
\text { No hay datos sobre el tratamiento } \\
\text { recibido por ninguno de los } \\
\text { pacientes. }\end{array}$ & Linfopenia & $\begin{array}{l}\text { Rayos X de tórax: } \\
\text { anormalidades } \\
\text { intersticiales, } \\
\text { derrames } \\
\text { pleurales, } \\
\text { opacidades } \\
\text { irregulares o en } \\
\text { vidrio esmerilado. } \\
\text { USG de tórax: } \\
\text { síndrome } \\
\text { intersticial } \\
\text { sonográfico. }\end{array}$ \\
\hline $\begin{array}{l}\text { Patel } \\
\text { etal. }\end{array}$ & $1 / 5 / 20$ & USA & 1 & 0 & 1 & 12 & $1 \mathrm{~F}$ & $\begin{array}{l}\text { Fiebre, tos no productiva, dos días } \\
\text { de vómitos no sanguinolentos, } \\
\text { disnea, disminución de los sonidos } \\
\text { respiratorios de forma difusa, } \\
\text { petequias y hematuria. Desarrolló } \\
\text { SDRA y por ello se ingresó a UCIP. } \\
\text { Se manejó con óxido nítrico } \\
\text { inhalado y ventilación mecánica. } \\
\text { Después de administrar } \\
\text { azitromicina e hidroxicloroquina } \\
\text { sin mejoría, recibió tocilizumab y } \\
\text { remdesivir. }\end{array}$ & $\begin{array}{l}\text { Trombocitopenia } \\
\text { grave; } \\
\text { PCR, } \\
\text { procalcitonina y } \\
\text { ferritina, } \\
\text { elevadas. }\end{array}$ & $\begin{array}{l}\text { Rayos X de tórax: } \\
\text { opacidades } \\
\text { bilaterales difusas } \\
\text { y derrame pleural } \\
\text { pequeño. }\end{array}$ \\
\hline
\end{tabular}




\begin{tabular}{|c|c|c|c|c|c|c|c|c|c|c|}
\hline Fuente & Publicación & País & \#Ptes. & $\begin{array}{l}<10 \\
\text { años }\end{array}$ & $\begin{array}{l}\text { 10-19 } \\
\text { años }\end{array}$ & Rango & Sexo & Sintomatología/ tratamiento & Laboratorio & Imagenología \\
\hline $\begin{array}{l}\text { Trogen } \\
\text { et al. }\end{array}$ & $4 / 6 / 20$ & USA & 1 & 0 & 1 & $\begin{array}{l}17 \\
\text { años }\end{array}$ & $1 \mathrm{M}$ & $\begin{array}{l}\text { Varón obeso de } 17 \text { años, se } \\
\text { presentó a la emergencia con } \\
\text { historia de siete días de fiebre, } \\
\text { dolor de cuello y síntomas } \\
\text { gastrointestinales (nauseas, dolor } \\
\text { abdominal, diarrea). } \\
\text { Ingresó en la UCIP por presentar } \\
\text { choque séptico no refractario a } \\
\text { tratamiento con líquidos. Ameritó } \\
\text { oxígeno suplementario y recibió } \\
\text { hidroxicloroquina } 400 \text { mg BID } \\
\text { el día uno, seguido de un plan } \\
\text { de } 200 \text { mg BID a completar } \\
\text { cinco días más; sin embargo, } \\
\text { fue interrumpido el día tres por } \\
\text { mostrar en el EKG un intervalo } \\
\text { QT prolongado. Además, recibió } \\
\text { anticoagulación con enoxaparina. } \\
\text { Al ser dado de alta completó dos } \\
\text { semanas más de apixaban. }\end{array}$ & $\begin{array}{l}\text { PCR, ferritina, } \\
\text { troponina I, } \\
\text { dímero-D y } \\
\text { creatinina, } \\
\text { elevados. }\end{array}$ & $\begin{array}{l}\text { Rayos X de tórax: } \\
\text { opacidades en } \\
\text { vidrio esmerilado } \\
\text { en los lóbulos } \\
\text { inferiores. } \\
\text { La ecocardiografía } \\
\text { y la resonancia } \\
\text { magnética } \\
\text { cardíaca } \\
\text { confirmaron } \\
\text { miocarditis aguda. }\end{array}$ \\
\hline $\begin{array}{l}\text { Torres } \\
\text { et al. }\end{array}$ & $28 / 8 / 20$ & Chile & 27 & ND & ND & $\begin{array}{l}0-14 \\
\text { años }\end{array}$ & $\begin{array}{l}14 \mathrm{M} \\
13 \mathrm{~F}\end{array}$ & $\begin{array}{l}\text { Fiebre, dolor abdominal, diarrea, } \\
\text { vómitos, erupción cutánea, } \\
\text { inyección conjuntival y tos. } \\
\text { Más de la mitad de los niños } \\
\text { (59\%) requirieron admisión a } \\
\text { UCIP, diagnosticándoles MIS-C. Se } \\
\text { prescribieron antimicrobianos en } \\
\text { el } 73 \text { \% de los pacientes tratados } \\
\text { en un servicio hospitalario y en el } \\
\text { 100 \% de los pacientes tratados en } \\
\text { UCIP. Se cumplió anticoagulación } \\
\text { en } 18 \text { pacientes, } 16 \text { recibieron } \\
\text { un régimen de profilaxis y dos } \\
\text { recibieron dosis de tratamiento. } \\
\text { Tratamiento antiinflamatorio } \\
\text { especíico: } 24 \text { pacientes recibieron } \\
\text { IGIV y/o corticosteroides } \\
\text { sistémicos; de estos, doce } \\
\text { niños recibieron ambos (IGIV + } \\
\text { corticosteroides), siete solo IGIV } \\
\text { y cinco solo corticosteroides. De } \\
\text { los } 17 \text { pacientes que recibieron } \\
\text { corticosteroides, } 15 \text { fueron } \\
\text { tratados con metilprednisolona, } \\
\text { uno con dexametasona y uno } \\
\text { con hidrocortisona. Además, } \\
\text { se sospechó un síndrome de } \\
\text { tormenta de citocinas en dos } \\
\text { pactró tocilizumab. }\end{array}$ & $\begin{array}{l}\text { Al ingreso, los } \\
\text { parámetros de } \\
\text { laboratorio fueron } \\
\text { compatibles con } \\
\text { inflamación aguda } \\
\text { en la mayoría de los } \\
\text { niños, con aumento } \\
\text { del dímero D y la } \\
\text { PCR; además de } \\
\text { linfopenia, anemia } \\
\text { y plaquetopenia. }\end{array}$ & $\begin{array}{l}\text { Rayos X de tórax y } \\
\text { TAC de tórax: } \\
\text { no se encontraron } \\
\text { datos } \\
\text { contribuyentes. } \\
\text { Ecocardiografía: } \\
\text { se detectó en } \\
12 \text { pacientes } \\
\text { disfunción } \\
\text { miocárdica y/o } \\
\text { refringencia de las } \\
\text { arterias coronarias } \\
\text { y/o derrame } \\
\text { pericárdico. }\end{array}$ \\
\hline
\end{tabular}




\begin{tabular}{|c|c|c|c|c|c|c|c|c|}
\hline Fuente & Publicación & País & \#Ptes. & $\begin{array}{l}<10 \\
\text { años }\end{array}$ & $\begin{array}{l}\text { 10-19 } \\
\text { años }\end{array}$ & Rango & Sexo & Sintomatología/ tratamiento \\
\hline $\begin{array}{l}\text { Mahajan } \\
\text { et al. }{ }^{31}\end{array}$ & $8 / 9 / 20$ & USA & 1 & 1 & 0 & 8 años & $1 \mathrm{M}$ & $\begin{array}{l}\text { Dolor abdominal periumbilical } \\
\text { leve y dos días de fiebre sin } \\
\text { respuesta a los antipiréticos. Leve } \\
\text { dolor a la palpación abdominal en } \\
\text { el área periumbilical, sin } \\
\text { signos peritoneales. El paciente } \\
\text { fue dado de alta con diagnóstico } \\
\text { de gastritis leve, gastroenteritis } \\
\text { temprana y estreñimiento. }\end{array}$ \\
\hline
\end{tabular}

Regresó al día siguiente debido a fiebre alta persistente, dolor abdominal continuo y disminución del apetito. Estaba febril y taquicárdico y al examen físico se le detectó nuevamente dolor periumbilical leve. A la mañana siguiente, aproximadamente

12 horas después del ingreso, y cinco días desde el inicio de los síntomas, continuó con fiebre alta y taquicardia persistente, a pesar del uso de antipiréticos y líquidos intravenosos. El dolor abdominal se generalizó, sin rigidez ni signos peritoneales. La frecuencia cardíaca se mantuvo elevada para la edad, incluso estando afebril.

A las 18 horas de ingreso, los diagnósticos diferenciales incluyeron: enfermedad de Kawasaki (EK) atípica, miocarditis viral y sindrome de Kawasaki-like, relacionados con COVID-19 (lo que más tarde se conoció como MIS-C).

Se le inició aspirina a dosis altas e IGIV, como tratamiento de una presunta EK atípica, basada en los hallazgos del ecocardiograma.

A las 24 horas de ingreso desarrolló hipotensión, extremidades frías con pulsos disminuidos y taquipnea. Fue trasladado a UCIP para un seguimiento más cercano, donde se descompensó rápidamente debido a un choque cardiogénico que condujo a hipoxia aguda e insuficiencia respiratoria, con edema pulmonar y lesión aguda del riñón. Fue intubado y se le inició soporte inotrópico.

IgM e IgG anti SARS-CoV-2 resultaron positivas, y se le diagnosticó formalmente MIS-C pos viral.

Recibió remdesivir, anakinra, metilprednisolona y heparina de bajo peso molecular.

El paciente fue extubado con éxito y fue dado de alta sin complicaciones cardiopulmonares adicionales, o anomalías de laboratorio.
Laboratorio

Imagenología

Trombocitopenia

USG

leve y PCR elevada.

abdominal:

inconclusa.

Resonancia

magnética

abdominal:

Alteraciones en engrosamiento todas las siguientes pruebas: difuso de las pruebas: paredes del intestino delgado VES y grueso.

Troponina

Pro-BNP

$\mathrm{DHL}$

Rayos X de tórax:

Fibrinógeno

no anomalías

Procalcitonina cardiopulmonares.

Ferritina

dímero-D

Ecocardiograma: reducción de la

tensión

longitudinal

máxima global,

ectasia

significativa de la arteria coronaria descendente anterior izquierda, sin aneurismas; función sistólica biventricular normal, no derrame pericárdico. 


\begin{tabular}{|c|c|c|c|c|c|c|c|c|c|c|}
\hline Fuente & Publicación & País & \#Ptes. & $\begin{array}{l}<10 \\
\text { años }\end{array}$ & $\begin{array}{l}\text { 10-19 } \\
\text { años }\end{array}$ & Rango & Sexo & Sintomatología/ tratamiento & Laboratorio & Imagenología \\
\hline $\begin{array}{l}\text { Matsuda } \\
\text { et al.32 }\end{array}$ & $6 / 10 / 20$ & Brasil & 1 & 0 & 1 & $\begin{array}{l}10 \\
\text { años }\end{array}$ & M & $\begin{array}{l}\text { Siete días de fiebre, dolor } \\
\text { abdominal y diarrea. Al examen } \\
\text { físico afebril, deshidratado, } \\
\text { postrado y con eritema } \\
\text { conjuntival. Tuvo hipoxemia de } \\
93,5 \% \text {, ascitis, derrame pleural } \\
\text { y pericarditis. Se diagnosticó } \\
\text { clínicamente como MIS-C. } \\
\text { Desde su ingreso, recibió } \\
\text { ceftriaxona por } 10 \text { días, } \\
\text { oseltamivir durante cinco días y } \\
\text { un macrólido durante } 8 \text { días (4 } \\
\text { días de claritromicina seguidos } \\
\text { de cuatro días de azitromicina). } \\
\text { Se administraron tres dosis } \\
\text { de hidroxicloroquina. El niño } \\
\text { evolucionó a resolución y egresó } \\
\text { después de } 14 \text { días. Se almacenó } \\
\text { a - } 80^{\circ} \mathrm{C} \text { una muestra de plasma } \\
\text { adquirida al alta, resultó reactiva } \\
\text { en cuatro pruebas rápidas para } \\
\text { SARS-CoV-2. }\end{array}$ & $\begin{array}{l}\text { Anemia, } \\
\text { leucocitosis a } \\
\text { predominio } \\
\text { polimorfonuclear, } \\
\text { linfopenia, } \\
\text { niveles elevados } \\
\text { de marcadores } \\
\text { inflamatorios, } \\
\text { entre ellos PCR, } \\
\text { dímero D, ferritina y } \\
\text { fibrinógeno. }\end{array}$ & $\begin{array}{l}\text { TAC de tórax: } \\
\text { opacificación en } \\
\text { vidrio esmerilado, } \\
\text { derrame pleural } \\
\text { bilateral escaso. } \\
\text { Después de cinco } \\
\text { días, la TAC de } \\
\text { tórax mostró } \\
\text { consolidación del } \\
\text { lóbulo inferior del } \\
\text { pulmón izquierdo, } \\
\text { con broncograma } \\
\text { aéreo y atelectasia, } \\
\text { derrame pleural } \\
\text { bilateral y derrame } \\
\text { pericárdico. } \\
\text { TAC de abdomen: } \\
\text { adenitis } \\
\text { mesentérica y } \\
\text { ascitis. }\end{array}$ \\
\hline $\begin{array}{l}\text { Meyer } \\
\text { et al. }{ }^{33}\end{array}$ & $26 / 11 / 20$ & USA & 4 & 0 & 4 & $\begin{array}{l}\text { 11-17 } \\
\text { años }\end{array}$ & $\begin{array}{l}3 \mathrm{M} \\
1 \mathrm{~F}\end{array}$ & $\begin{array}{l}\text { Se describe uno de los cuatro } \\
\text { casos de jóvenes que fueron } \\
\text { intervenidos por apendicitis } \\
\text { aguda en el contexto de una } \\
\text { infección activa por SARS-CoV-2, } \\
\text { diagnosticada por RT-PCR. } \\
\text { Niña hispana de } 11 \text { años, obesa, } \\
\text { sin antecedentes de enfermedad, } \\
\text { que se presentó con dos días } \\
\text { de dolor abdominal, vómitos } \\
\text { recurrentes, sin sangre o bilis, } \\
\text { y fiebre. Ante la posibilidad de } \\
\text { apendicitis aguda se indica TAC } \\
\text { abdominal. Al examen físico fue } \\
\text { notable la sensibilidad difusa a la } \\
\text { palpación, más pronunciada en } \\
\text { el cuadrante inferior derecho, con } \\
\text { defensa y rebote. } \\
\text { Se le inició ceftriaxona y } \\
\text { metronidazol y se le efectuó } \\
\text { apendicetomía laparoscópica. } \\
\text { El apéndice resecado estaba } \\
\text { perforado y necrótico. } \\
\text { Fue dada de alta al sexto día } \\
\text { posoperatorio, a completar diez } \\
\text { días de amoxicilina-clavulanato oral. }\end{array}$ & $\begin{array}{l}\text { Leucocitosis de } \\
15400 / \mathrm{mm}^{3} \text { a } \\
\text { predominio PMN } \\
(81 \%) .\end{array}$ & $\begin{array}{l}\text { TAC abdominal: } \\
\text { apéndice dilatado } \\
\text { Ileno de líquido } \\
\text { con inflamación } \\
\text { circundante, } \\
\text { consistente } \\
\text { con apendicitis } \\
\text { aguda sin } \\
\text { perforación o } \\
\text { absceso. }\end{array}$ \\
\hline
\end{tabular}

A menos que se especifique, los pacientes no ameritaron UCIP y no hubo mortalidad, sin complicaciones al egreso, con un rango de estadia hospitalaria de 1 a 24 días. ND: no datos; PCR: proteína c reactiva; VES: velocidad de eritrosedimentación; USG: ultrasonografía; TAC: tomografía axial computarizada; CK-MB: creatina quinasa-banda miocárdica; M: masculino; F: femenino; UCIP: unidad de cuidados intensivos pediátricos; SDRA: síndrome de dificultad respiratoria aguda; BID: cada 12 horas; EKG: electrocardiograma; MISC: síndrome inflamatorio multisistémico en niños; IGIV: inmunoglobulina humana intravenosa; Pro-BNP: péptido natriurético procerebral; DHL: deshidrogenasa láctica; EK: enfermedad de Kawasaki; RT-PCR: reacción en cadena de la polimerasa con transcriptasa inversa; IgM: inmunoglobulina M; Ig G: inmunoglobulina G. 
infarto cerebrovascular. A este paciente se le detectó SARS-CoV-2 pos mortem.

Consideraron que se trataba de un nuevo fenómeno fisiopatológico, afectando a niños que se infectaban con SARS-CoV-2, manifestándose como un síndrome hiperinflamatorio con falla multiorgánica similar al KDSS. Pero al avanzar la pandemia, se determinó que se trataba de una entidad clínica diferente. En efecto, posterior a lo informado por Riphagen et al. ${ }^{35}$, varios autores de Europa, los Estados Unidos y Latinoamérica, reportaron casos de un síndrome inflamatorio multisistémico en niños, de etiología desconocida y temporalmente relacionado con el SARS-CoV-2 ${ }^{37-40}$. Aunque se presenta con poca frecuencia, se asocia con un número considerable de ingresos a UCIP y en raras ocasiones, con la muerte ${ }^{37-39}$. Esta forma más grave de COVID-19 se ha descrito con mayor frecuencia en categorías étnicas específicas de niños, en particular niños afroamericanos, afrocaribeños y latinos $s^{39,41}$. Se presenta con mayor frecuencia en escolares, desconociéndose aún la razón de esta particularidad.

Fue nombrado por el Royal College of Paediatrics and Child Health del Reino Unido (RCPCH, por sus siglas en inglés) como síndrome inflamatorio multisistémico pediátrico (PIMS, por sus siglas en inglés) o síndrome inflamatorio multisistémico pediátrico temporalmente asociado a SARSCoV-2 (PIMS-TS, por sus siglas en inglés), estableciendo sus criterios diagnósticos el 1 de mayo de 202042. Dos semanas después, los $\mathrm{CDC}^{43}$ y la OMS $\mathrm{OMS}^{44}$ lo nombraron síndrome inflamatorio multisistémico en niños (MIS-C, por sus siglas en inglés), estableciendo a la vez, su criterios diagnósticos.

La definición en todas las organizaciones se basa en 6 elementos principales: edad pediátrica, persistencia de la fiebre, presencia de marcadores inflamatorios, signos o síntomas de disfunción orgánica, ausencia de un diagnóstico alternativo y una relación temporal con la infección o exposición al SARS-CoV-2. Mientras que la definición de RCPCH de PIMS-TS reconoce la asociación temporal con COVID-19, no requiere prueba de infección o exposición para que se cumpla con la definición de caso, a diferencia de los criterios de los CDC y la OMS ${ }^{45}$.

Desde junio de 2020, varios informes de casos y series han informado de un síndrome inflamatorio multisistémico similar en adultos. Al 9 de octubre de 2020, veinte casos habían sido reportados al CDC ${ }^{46}$.

\section{Definición de caso de MIS-C se- gún los CDC}

Paciente $<21$ años que presenta fiebre ( $>$ $38.0{ }^{\circ} \mathrm{C}$ durante $\geq 24$ horas, o reporte de fiebre subjetiva que dura $\geq 24$ horas), evidencia de laboratorio de inflamación (que incluye, pero no se limita a, uno o más de los siguientes: PCR, VES, fibrinógeno, procalcitonina, dímero- $D$, ferritina, deshidrogenasa láctica, interleucina 6 o neutrófilos elevados; linfocitos reducidos y albúmina baja) y evidencia de enfermedad clínicamente grave que requiere hospitalización, con compromiso multisistémico involucrando $>2$ órganos (cardíaco, renal, respiratorio, hematológico, gastrointestinal, dermatológico o neurológico); no hay diagnósticos alternativos posibles; resultado positivo para infección actual o reciente de SARS-CoV-2 por RT-PCR, prueba de anticuerpos o prueba de antígenos o exposición a un caso sospechoso o confirmado de COVID-19 dentro de las 4 semanas previas al inicio de los síntomas. Algunas personas pueden cumplir criterios completos o incompletos para la enfermedad de Kawasaki. Sin embargo, en el contexto actual deben ser reportadas como MIS-C si cumplen la definición de caso. Se debe considerar la posibilidad de MIS-C en cualquier muerte pediátrica con evidencia de infección por SARS-CoV-2 ${ }^{47}$.

Al momento no se han realizado estudios que comparen la eficacia clínica de las diferentes opciones terapéuticas para MISC. Los tratamientos han consistido principalmente en cuidados de apoyo e intervenciones dirigidas contra el proceso inflamatorio subyacente. Las medidas de apoyo han incluido: resucitación con líquidos intravenosos, soporte inotrópico, soporte respiratorio y en casos raros, oxigenación por membrana extracorpórea (ECMO, por sus siglas en inglés). Las medidas antiinflamatorias han incluido el uso frecuente de inmunoglobulinas y esteroides. La aspirina se ha utilizado habitualmente debido a la preocupación por la afectación de las arterias coronarias. Los antibióticos se utilizan de forma rutinaria como profilaxis ante una posible sepsis bacteriana, mientras se esperan los resultados de los cultivos. La profilaxis antitrombótica se utiliza a menudo debido al estado de hipercoagulabilidad asociado típicamente con el MIS-C. Los pacientes con diagnóstico de MIS-C deben tener un seguimiento ambulatorio estricto, incluida una evaluación por cardiología pediátrica de 2 a 3 semanas después del alta ${ }^{47}$.

Para una ampliación sobre el abordaje diagnóstico y terapéutico del MIS-C, o PIMS$\mathrm{TS}$, se recomienda revisar las Interim guidance on multisystem inflammatory syndrome in children (MIS-C) ${ }^{48}$ de la Academia Americana de Pediatría y los consensos de expertos 
elaborados utilizando del método Delphi: el National consensus management pathway for paediatric inflammatory multisystem syndrome temporally associated with COVID-19 (PIMS-TS) $^{49}$, del PIMS-TS National Consensus Management Study Group (Reino Unido), y las Clinical guidance for multisystem inflammatory syndrome in children associated with SARS-COV-2 and hyperinflammation in pediatric COVID-19: version 150, del American College of Rheumatology.

\section{Conclusiones}

Las estadísticas iniciales de la pandemia, elaboradas en China, orientaron a que los niños y adolescentes serían afectados de forma esporádica por el SARS-CoV-2. Sin embargo, a medida la epidemia se distribuyó globalmente y se convirtió en una pandemia, se evidenció el compromiso de los pacientes en edad pediátrica.

Las infecciones pediátricas se han caracterizado por presentarse en las etapas iniciales de la epidemia en cada país, para luego disminuir de forma lenta y constante. El sexo masculino se infecta más frecuentemente que el femenino; sin embargo, el sexo masculino no es un factor de riesgo independiente de COVID-19 grave.

La sintomatología más frecuente en niños y adolescentes es: fiebre, tos seca, faringitis, dolor abdominal y diarrea. El hallazgo de laboratorio más frecuente es la linfopenia y en los casos graves, se agregan las elevaciones importantes de la PCR, la procalcitonina, el dímero-D y la CK-MB. En rayos $X$ y la TAC de tórax el hallazgo más frecuente son las opacidades pulmonares en vidrio esmerilado.

Los niños presentan menos infecciones y menos gravedad que los adultos. La forma de presentación más frecuente en la edad pediátrica es la enfermedad leve; sin embargo, lactantes y preescolares han presentado de forma ocasional, cuadros graves. La mayoría de pacientes que se ingresan a las UCIP presentan una o más comorbilidades.

La excreción continua y prolongada del virus en las secreciones respiratorias y las heces, tanto de pacientes sintomáticos como asintomáticos, debe evaluarse con detenimiento, con el fin de determinar su impacto en la salud pública global. A la vez, la posible transmisión fecal-oral del virus debe tomarse en consideración, al establecer los protocolos de prevención tanto en el ámbito hospitalario como en el comunitario.

A partir de esta pandemia, se debe incluir a COVID-19 como parte del diagnóstico diferencial de la fiebre sin signos de localización en pediatría, sobre todo en aquellos pacientes que presenten criterios clínicos,

\section{de laboratorio o imagen de MIS-C.
Referencias bibliográficas}

1. The Novel Coronavirus Pneumonia Emergency Response Epidemiology Team. The epidemiological characteristics of an outbreak of 2019 novel coronavirus diseases (COVID-19). China CDC. 2020. Disponible en: http://weekly.chinacdc.cn/fileCCDCW/ journal/article/ccdcw/2020/8/PDF/COVID19.pdf

2. Newland JG. Children in the eye of the pandemic storm -lessons from New York City. JAMA Pediatr. 2020;e202438. DOI: 10.1001/jamapediatrics.2020.2438

3. Garazzino S. Multicentre Italian study of SARS-CoV-2 infection in children and adolescents, preliminary data as at 10 April 2020. Eurosurveillance. 2020;25(18):2-5. DOI: 10.2807/1560-7917.ES.2020.25.18.2000600

4. COVID-19 National Emergency Response Center, Epidemiology and Case Management Team, Korea Centers for Disease Control and Prevention. Coronavirus Disease-19: The first 7,755 cases in the Republic of Korea. Osong Public Health Res Perspect. 2020;11(2):85-90. DOI: 10.24171/j. phrp.2020.11.2.05

5. Dong Y. Epidemiology of COVID-19 among children in China. Pediatrics. 2020; e20200702. DOI: 10.1542/peds.2020-0702

6. Cai J. A Case series of children with 2019 novel coronavirus infection: clinical and epidemiological features. Clin Infect Dis. 2020;ciaa198. DOl: 10.1093/cid/ciaa198

7. Cheung KS. Gastrointestinal manifestations of SARS-COV-2 infection and virus load in fecal samples from the Hong Kong cohort and systematic review and meta-analysis. Gastroenterology. 2020. DOI: 10.1053/j. gastro.2020.03.065

8. Passanisi S. Are children most of the submerged part of SARS-CoV-2 iceberg? Front Pediatr. 2020;8:213. DOI: 10.3389/ fped.2020.00213

9. Cruz AT. COVID-19 in children: initial characterization of the pediatric disease. Pediatrics. 2020;e20200834. DOI: 10.1542/ peds.2020-0834

10. Centers for Disease Control and Prevention. COVID-19 Response Team. Coronavirus disease 2019 in children — United States, February 12-April 2, 2020. Morbidity and Mortality Weekly Report 422 MMWR. 2020;69(14):422-6. Disponible en: https:// www.cdc.gov/mmwr/volumes/69/wr/pdfs/ $\underline{\text { mm6914e4-H.pdf }}$

11. Parri N. Children with Covid-19 in pediatric emergency departments in Italy. N Engl J Med. 2020;NEJMc2007617. DOI: 10.1056/ NEJMc2007617 
12. Society of Pediatrics, Chinese Medical Association. Recommendations for the diagnosis, prevention and control of the 2019 novel coronavirus infection in children (First interim edition). Zhonghua Er Ke Za Zhi. 2020;58(0):E004. DOI:10.3760/cma.j.is sn.0578-1310.2020.03.001

13. Buonsenso D. Toward a clinically based classification of disease severity for paediatric COVID-19. Lancet Infect Dis. 2020;S1473309920303960. DOI:10.1016/ S1473-3099(20)30396-0

14. Hoang A. COVID-19 in 7780 pediatric patients: A systematic review. EClinicalMedicine. 2020;100433. DOl:10.1016/j.eclinm.2020.100433

15. Pourbagheri-Sigaroodi A. Laboratory findings in COVID-19 diagnosis and prognosis. Clinica Chimica Acta. 2020;510:475-482. DOI: 10.1016/j. cca.2020.08.019

16. Katal S. Imaging Findings of SARS-CoV-2 Infection in Pediatrics: a systematic review of coronavirus disease 2019 (COVID-19) in 850 Patients. Acad Radiol. 2020;27(11):16081621. DOI: 10.1016/j.acra.2020.07.031

17. Parrón M. Signo del halo en la tomografía computarizada de tórax: diagnóstico diferencial con correlación anatomopatológica. Arch Bronconeumol. 2008;44(7):386-92. DOI: 10.1016/S03002896(08)70453-8

18. Manzano AC. Patrón en adoquín desordenado (Crazy paving). Revista Colombiana de Neumología. 2020;24(1):4748. DOI: 10.30789/rcneumologia.v24. n1.2012.205

19. NIH COVID-19 Treatment Guidelines. Special considerations in children. National Institutes of Health. 2020. Consultado el 8 de diciembre de 2020. Disponible en: https:// www.covid19treatmentguidelines.nih.gov/ special-populations/children/

20. Shen K-L. Diagnosis and treatment of 2019 novel coronavirus infection in children: a pressing issue. World J Pediatr. 2020;s12519020-00344-6. DOI: 10.1007/s12519-02000344-6

21. Chan JF-W. A familial cluster of pneumonia associated with the 2019 novel coronavirus indicating person-to-person transmission: a study of a family cluster. The Lancet. 2020; 395(10223):514-23. DOI: 10.1016/501406736(20)30154-9

22. Feng K. Analysis of $\mathrm{CT}$ features of 15 Children with 2019 novel coronavirus infection. Chin J Pediatr. 2020;58(0):E007. DOI: 10.3760/cma.j.issn.0578-1310.2020.0007

23. Xia W. Clinical and CT features in pediatric patients with COVID-19 infection: different points from adults. Pediatr Pulmonol. 2020;55(5):1169-74. DOI: 10.1002/ ppul.24718
24. Qiu H. Clinical and epidemiological features of 36 children with coronavirus disease 2019 (COVID-19) in Zhejiang, China: an observational cohort study. Lancet Infect Dis. 2020;20(6):689-96. DOI: 10.1016/S14733099(20)30198-5

25. Liu W. Detection of Covid-19 in children in early January 2020 in Wuhan, China. N Eng J Med. 2020;382(14):1370-1. DOI: 10.1056/ NEJMc2003717

26. LUX. SARS-CoV-2 infection in children. N Engl J Med. 2020;382(17):1663-5. DOI: 10.1056/NEJMc2005073

27. Nathan N. Atypical presentation of COVID-19 in young infants. The Lancet. 2020;395(10235):1481. DOI: 10.1016/ S01406736(20)30980-6

28. Patel PA. Severe pediatric COVID-19 presenting with respiratory failure and severe thrombocytopenia. Pediatrics. 2020 e20201437. DOI: 10.1542/peds.2020-1437

29. Trogen B. COVID-19-associated myocarditis in an adolescent. Pediatr Infect Dis J. 2020. DOI: $10.1097 /$ INF.0000000000002788

30. Torres JP. Multisystem inflammatory syndrome in children (MIS-C): Report of the clinical and epidemiological characteristics of cases in Santiago de Chile during the SARS-CoV-2 pandemic. International Journal of Infectious Diseases. 2020;100:75-81. DOI: 10.1016/j.ijid.2020.08.062

31. Mahajan N. Case of multisystem inflammatory syndrome in children presenting as fever and abdominal pain. BMJ Case Rep. 2020;13:e237306. DOI: 10.1136/bcr-2020-237306

32. Matsuda E. COVID-19 in children: a case report of multisystem inflammatory syndrome (MIS-C) in São Paulo, Brazil. Braz J Infect Dis. 2020;24(6):580-582. DOI: 10.1016/j.bjid.2020.09.002

33. Meyer JS. Acute appendicitis in four children with SARS-CoV-2 infection. J Pediatr Surg Case Rep. 2021;64:101734. DOI: 10.1016/j. epsc.2020.101734

34. Shekerdemian LS. Characteristics and outcomes of children with coronavirus disease 2019 (COVID-19) infection admitted to US and Canadian pediatric intensive care units. JAMA Pediatr. 2020. DOI: 10.1001/ jamapediatrics.2020.1948

35. Riphagen S. Hyperinflammatory shock in children during COVID-19 pandemic. The Lancet. 2020;395(10237):1607-8. DOI: 10.1016/S0140-6736(20)31094-1

36. Zhang M-M. Clinical analysis of Kawasaki disease shock syndrome. Chin Med J. 2017;130(23):2891-2. DOI: 10.4103/03666999.219151

37. Whittaker E. Clinical Characteristics of 58 Children With a Pediatric Inflammatory Multisystem Syndrome Temporally Associated With SARS-CoV-2. JAMA. 
2020;324(3):259-269. DOI:10.1001/

jama.2020.10369

38. Feldstein LR. Multisystem inflammatory syndrome in U.S. children and adolescents. N Engl J Med 2020;383:334-346. DOI: 10.1056/NEJMoa2021680

39. Antúnez-Montes OY. COVID-19 and multisystem inflammatory syndrome in Latin American children. Pediatr Infect Dis J. 2021;40(1):e1-e6. DOl: 10.1097/ INF.0000000000002949

40. Ulloa-Gutierrez R. Multisystem Inflammatory Syndrome Surveillance and COVID-19 in Latin America. Pediatr Infect Dis J. 2020;39(12):e473-e474. DOI: 10.1097/ INF.0000000000002901

41. Godfred-Cato S. COVID-19-associated multisystem inflammatory syndrome in children - United States, March-July 2020. MMWR. 2020;69(32):1074-1080. Disponible en: https://www.cdc.gov/mmwr/ volumes/69/wr/pdfs/mm6932e2-H.pdf

42. RCPCH. Paediatric multisystem inflammatory syndrome temporally associated with COVID-19 (PIMS) - guidance for clinicians. Royal College of Paediatrics and Child Health. 2020. Consultado del 12 de diciembre de 2020. Disponible en: $\underline{\text { https://www.rcpch.ac.uk/resources/ }}$ paediatric-multisystem-inflammatorysyndrome-temporally-associated-covid-19pims-guidance

43. CDC. Emergency preparedness and response. Health Alert Network 00432. Centers for Disease Control and Prevention. 2020. Consultado del 12 de diciembre de 2020. Disponible en: https://emergency.cdc. gov/han/2020/han00432.asp

44. WHO. Multisystem inflammatory syndrome in children and adolescents with COVID-19 Scientific Brief. World Health Organization. 2020. Consultado del 12 de diciembre de 2020. Disponible en: https://www.who. int/publications/i/item/multisystem- inflammatory-syndrome-in-children-andadolescents-with-covid-19

45. Ahmed M. Multisystem inflammatory syndrome in children: A systematic review. EClinicalMedicine. 2020;26(1005272020): 1-16. DOI: 10.1016/j.eclinm.2020.100527

46. Morris S-B. Case series of multisystem inflammatory syndrome in adults associated with SARS-CoV-2 infection - United Kingdom and United States, March-August 2020. MMRW. 2020; 69(40):1450-1456. Disponible en: https://www.cdc.gov/ mmwr/volumes/69/wr/pdfs/mm6940e1-H. $\underline{\mathrm{pdf}}$

47. CDC. Multisystem Inflammatory Syndrome (MIS-C). Case Definition for MIS-C. Centers for Disease Control and Prevention. 2020. Consultado del 12 de diciembre de 2020. Disponible en: https://www.cdc.gov/mis-c/ $\underline{\mathrm{hcp} /}$

48. AAP. Multisystem Inflammatory Syndrome in Children (MIS-C) Interim Guidance. American Academy of Pediatrics. 2020. Consultado el 12 de diciembre de 2020. Disponible en: https://services.aap.org/en/ pages/2019-novel-coronavirus-covid-19infections/clinical-guidance/multisysteminflammatory-syndrome-in-children-mis-cinterim-guidance/

49. Harwood R. A national consensus management pathway for paediatric inflammatory multisystem syndrome temporally associated with COVID-19 (PIMSTS): results of a national Delphi process. The Lancet Child \& Adolescent Health. 2020. DOI: 10.1016/S2352-4642(20)30304-7

50. Henderson LA. American College of Rheumatology clinical guidance for multisystem inflammatory syndrome in children associated with SARS-COV-2 and hyperinflammation in pediatric COVID-19: version 1. Arthritis and Rheumatology. 2020;72(11):1791-1805. DOI: 10.1002/ art.41454 